\title{
Left ventricular structural and functional changes evaluated by echocardiography and two-dimensional strain in patients with sickle cell disease
}

\author{
Ricardo Bedirian ${ }^{1,2}$, Andrea Ribeiro Soares ${ }^{1,3}$, Maria Christina Maioli ${ }^{1,3}$, \\ Jussara Fonseca Fernandes de Medeiros ${ }^{3}$, Agnaldo José Lopes ${ }^{1,4}$, Marcia Bueno Castier ${ }^{1,5}$
}

\begin{abstract}
${ }^{1}$ Post-graduate Program in Medical Sciences, State University of Rio de Janeiro, Rio de Janeiro, Brazil

${ }^{2}$ Department of Clinical Medicine, State University of Rio de Janeiro, Rio de Janeiro, Brazil ${ }^{3}$ Department of Hematology, State University of Rio de Janeiro, Rio de Janeiro, Brazil ${ }^{4}$ Department of Pneumology, State University of Rio de Janeiro, Rio de Janeiro, Brazil ${ }^{5}$ Department of Cardiology, State University of Rio de Janeiro, Rio de Janeiro, Brazil
\end{abstract}

Submitted: 7 October 2015

Accepted: 5 February 2016

Arch Med Sci 2018; 14, 3: 493-499

DOI: https://doi.org/10.5114/aoms.2016.58785

Copyright $\odot 2016$ Termedia \& Banach

\section{Abstract}

Introduction: Patients with sickle cell disease have increased left ventricular size, which is not usually accompanied by changes in systolic function indexes. We assessed echocardiographic abnormalities present in patients with sickle cell anemia (SCA) and compared echocardiographic parameters to other sickle cell diseases (OSCD).

Material and methods: A blind cross-sectional study with 60 patients with SCA and 16 patients with OSCD who underwent transthoracic echocardiography was performed.

Results: Echocardiographic findings were: left atrial volume index 47.7 $\pm 11.5 \mathrm{ml} / \mathrm{m}^{2}$ in SCA group and $31.7 \pm 8.42 \mathrm{ml} / \mathrm{m}^{2}$ in OSCD group $(p<0.001)$; left ventricular diastolic diameter index $3.47 \pm 0.37 \mathrm{~cm} / \mathrm{m}^{2}$ in SCA group and $2.97 \pm 0.41 \mathrm{~cm} / \mathrm{m}^{2}$ in OSCD group $(p<0.001)$; left ventricular systolic diameter index $2.12 \pm 0.31 \mathrm{~cm} / \mathrm{m}^{2}$ in SCA group and $1.86 \pm 0.28 \mathrm{~cm} / \mathrm{m}^{2}$ in OSCD group $(p<0.001)$. There were no differences in the left ventricular ejection fraction: $68.2 \pm 6.69 \%$ in SCA group and $67.1 \pm 6.21 \%$ in OSCD group $(p=0.527)$. The ratio between mitral $E$ wave and mean mitral annulus e' wave velocities was higher in the SCA group (7.72 \pm 1.54 vs. $6.70 \pm 1.65 ; p=0.047)$. Mitral A wave correlated significantly with hemoglobin levels $(r=-0.340 ; p=0.032)$.

Conclusions: There was an increase of left ventricular and left atrial sizes in patients with SCA, compared to patients with OSCD, without changes in systolic or diastolic function in both groups. This could be due to the hyperkinetic state due to the more severe anemia in the SCA subjects.

Key words: sickle cell disease, hemoglobinopathies, left ventricle, systolic function, diastolic function.

\section{Introduction}

Sickle cell disease is a group of hereditary hemolytic anemias, first described in 1910 [1], being the most common monogenic hereditary disease in the world. It affects approximately 100,000 individuals in the United States [2]. In Brazil, it is estimated that there are 35,000 people living with sickle cell disease (SCD), as a result of slave traffic for

\author{
Corresponding author: \\ Prof. Agnaldo José Lopes \\ Department of Pneumology \\ State University \\ of Rio de Janeiro \\ Rua Araguaia, 1266 \\ Bloco 1/405, Freguesia, \\ Jacarepaguá \\ 22745-271 Rio de Janeiro, \\ Brazil \\ Phone: +55 212125762030 \\ E-mail: \\ agnaldolopes.uerj@gmail.com
}


more than three hundred years [3]. Individuals who are homozygous for the hemoglobin $\mathrm{S}$ gene develop sickle cell anemia (SCA). When they are heterozygous for two hemoglobinopathies, they develop other sickle cell diseases (OSCD). Cardiac abnormalities are described in SCA, the most common being those related to pulmonary arterial hypertension and consequent right chamber overload [4]. There are also changes in left cavities, with increased left ventricular diameters [5-7]. These findings usually are not accompanied by systolic function changes $[8,9]$. The prevalence of left ventricle dysfunction in these patients is not estimated by large scale studies [5-9].

Left ventricular (LV) systolic dysfunction has been reported in older patients with SCA and is a poor prognostic indicator $[9,10]$. Pathophysiology of myocardial dysfunction is uncertain and appears to be multifactorial, involving not only a chronic hyperkinetic state, but also specific changes related to hemoglobinopathies [8]. In addition to a reduced amount of hemoglobin, another important element in the pathophysiology of SCA is changes in hemoglobin properties in deoxygenation conditions, which lead to red blood cell shape change and consequent microcirculation obstruction by sickle-shaped red blood cells, as well as interaction with leukocytes leading to local inflammation [9]. An intrinsic cardiomyopathy is also involved, even in non-anemic patients [11]. Myocardial ischemia or infarction, arrhythmia and sudden death are also described in these patients $[12,13]$.

New echocardiographic methods have been evaluated [14, 15]. Two-dimensional (2D) systolic strain, recently described in patients $18-40$ years of age, did not show changes in this population [16]. There are controversial speckle tracking studies in this area, showing abnormalities in children of Tanzania [17], and no changes in another study with adults [18]. Diastolic function may be impaired early and can even be detected in children [9]. Diastolic dysfunction implies poor prognosis, especially when associated with pulmonary hy pertension $[8,9,19]$. It may also be a predictor of future systolic dysfunction [20].

The aim of this study was to investigate echocardiographic abnormalities, including two-dimensional strain evaluation, in patients with SCA and compare them to data from patients with OSCD.

\section{Material and methods}

The study included 76 outpatients of both genders, with sickle cell disease, aged from 18 to 40 years, who attended at the Department of Hematology of Pedro Ernesto University Hospital of the State University of Rio de Janeiro. Sixty patients were homozygous with SCA and 16 doubly heterozygous, with OSCD (14 patients HbSC and 2 pa- tients HbSD). Exclusion criteria were recent history (less than 3 months) of blood transfusion and painful crisis, report or evidence of hypertension, cardiac arrhythmias, irregular heart rate, moderate or severe valve disease, coronary artery disease, cardiomyopathy, pericarditis, myocarditis or HIV infection.

All of the patients provided signed informed consent and study clarification forms before the study began. This study was approved by the Research Ethics Committee of the Pedro Ernesto University Hospital, under number 231.033, and was conducted in accordance with principles outlined in the Declaration of Helsinki. There is no external source of funding and none of the authors has any conflict of interest to declare.

Clinical evaluation and laboratory tests included measurement of weight and height, and tests for hemoglobin concentration. Transthoracic Doppler echocardiography was performed by the same examiner, using the iE33 system (Philips Medical Systems, MA, USA). Images were stored in digital media and reviewed by a second examiner, both unaware of the patients' group.

M-mode measurements were performed according to the American Society of Echocardiography recommendations [21]. LV mass was calculated by the Devereux method. Cavity dimensions and mass were indexed by body surface area calculated by the Dubois formula [21]. Two-dimensional parameters were left ventricle systolic and diastolic volumes and ejection fraction by modified Simpson method, right ventricle (RV) systolic and diastolic areas and systolic fractional shortening area, right atrium (RA) systolic area and volume and LA systolic volume by area-length method, LV outflow tract diameter, RV free wall thickness, and LV systolic strain [21, 22].

Left ventricular diastolic function was assessed by pulsed Doppler of the mitral inflow and by tissue Doppler obtained at the lateral and medial border of the mitral and tricuspid annulus in the apical four-chamber view [23]. E and A waves velocities, E/A ratio, isovolumetric relaxation time (IVRT) and deceleration time of early LV filling (DTE) in mitral flow were recorded. For right ventricular function, $E$ and $A$ wave velocities from tricuspid flow, right and left outflow tract velocities and integral (TVI) were recorded [24].

To estimate pulmonary artery systolic pressure (PASP), pulmonary flow acceleration time and tricuspid regurgitation jet velocity were used [21-25]. In order to evaluate RV function, S' peak velocity and the RV myocardial performance index (Tei index) were calculated from the tricuspid annulus tissue Doppler image (TDI); moreover, the tricuspid annulus peak systolic excursion (TAPSE) was also measured [26]. 
Forty-two patients of our sample were also evaluated with 2D Strain, in which images of the LV in apical four-, two- and three-chamber views were obtained and made suitable for analysis. The left ventricle was divided into 18 segments and 2D LV longitudinal strain was obtained for each segment using a software package (QLAB, Phillips, USA). Longitudinal strain was assessed in all six LV walls in the three apical views, and the average value of each wall on each view and the global strain value were used for comparisons with the controls [16, 27-29].

\section{Statistical analysis}

It was a blinded cross-sectional study, with comparison between SCA and OSCD patients. Statistical analysis was performed with SPSS 18.0 software (IBM, Chicago, IL, USA). Continuous variables were compared between groups (SCA and OSCD) by Student's $t$ test. Pearson's correlation coefficients $(r)$ were calculated to investigate the association between hemoglobin levels and echocardiographic parameters. $P$-values less than 0.05 were considered significant. The results were expressed as mean \pm SD or absolute number (\%).

\section{Results}

Patients in the SCA group presented significantly lower levels of hemoglobin than the OSCD group $(8.45 \pm 1.49 \mathrm{~g} / \mathrm{dl}$ in SCA group vs. 11.41 $\pm 0.81 \mathrm{~g} / \mathrm{dl}$ in OSCD group; $p<0.001)$ and higher heart rate $(78 \pm 12 \mathrm{bpm}$ in SCA group vs. $70 \pm 13$ bpm in OSCD group; $p=0.049$ ). Median age and body surface area were similar between groups. Forty-six $(60.5 \%)$ patients were treated with hydroxyurea (44 SCA patients and 2 OSCD patients). Moreover, 5 (6.58\%) patients were treated with an antihypertensive (angiotensin-converting enzyme inhibitor), all from the SCA group. Clinical parameters are presented in Table I.

Echocardiographic parameters obtained by M-mode and two-dimensional echocardiography
(Table II) showed significant enlargement of left cavity dimensions in SCA patients, but no change in ejection fraction obtained either by Teichholz or Simpson methods. LV and RV systolic function data were normal in all patients.

Diastolic function evaluated by E/A ratio, IVRT and DTE was normal in all patients; however, when evaluated by E/e' ratio it was abnormal (> 8) [24] in $35 \%$ of SCA patients and $6.3 \%$ of OSCD patients ( $p=0.002)$ (Table III). The E/e' was higher in the SCA group $(7.72 \pm 1.54$ in SCA group vs. $6.70 \pm 1.65$ in OSCD group; $p=0.047$ ). $\mathrm{E}$ and A wave velocities were greater in the SCA group (Table III). Changes in right cavity flow were detected with higher systolic blood pressure values of pulmonary artery and tricuspid regurgitant jet velocity in the SCA group. The S' wave tissue Doppler velocity at the tricuspid annulus was significantly higher in the SCA group. The cardiac index calculated from the LV outflow tract was significantly higher in the SCA group $(4.01 \pm 1.10 \mathrm{l} / \mathrm{min} /$ $\mathrm{m}^{2}$ in SCA group vs. $2.96 \pm 0.59 \mathrm{l} / \mathrm{min} / \mathrm{m}^{2}$ in OSCD group; $p<0.001$ ).

There were no differences between groups in two-dimensional LV strain values evaluation, as shown in Table IV. Assuming as a normal range value less than -18.9 [22], we found no differences between groups comparing the frequency of abnormal LV strain results.

Significant correlations were detected between hemoglobin levels and left ventricular diameters and mass indexes, left atrial volume index and mitral A wave velocity. Table $V$ shows correlations between hemoglobin levels and echocardiography parameters.

\section{Discussion}

Cardiac abnormalities in patients with sickle cell anemia have been previously described [30-33]. Adaption to anemia states, where oxygen-carrying capacity to tissues is reduced, involves a rise in cardiac output. This was corrob-

Table I. Clinical characteristics of the groups

\begin{tabular}{|lccc|}
\hline Parameter & $\begin{array}{c}\text { SCA } \\
(n=60)\end{array}$ & $\begin{array}{c}\text { OSCD } \\
(n=16)\end{array}$ & $P$-value \\
\hline Age [years] & $26 \pm 8$ & $25 \pm 6$ & 0.658 \\
\hline Male gender & $27(45 \%)$ & $7(43.8 \%)$ & 0.931 \\
\hline Afrodescendant & $60(100 \%)$ & $14(100 \%)$ & 1.000 \\
\hline BSA [m²] & $1.66 \pm 0.16$ & $1.72 \pm 0.22$ & 0.338 \\
\hline Hemoglobin $[\mathrm{g} / \mathrm{dll}]$ & $8.45 \pm 1.49$ & $11.42 \pm 0.81$ & $<0.001$ \\
\hline HR $[\mathrm{bpm}]$ & $77 \pm 12$ & $70 \pm 13$ & 0.049 \\
\hline SBP $[\mathrm{mm} \mathrm{Hg}]$ & $121.1 \pm 12.2$ & $116.0 \pm 7.61$ & 0.114 \\
\hline DBP $[\mathrm{mm} \mathrm{Hg}]$ & $76.5 \pm 11.7$ & $72.1 \pm 9.10$ & 0.204 \\
\hline
\end{tabular}

Values are expressed as means $\pm S D$ or number (\%). BSA - body surface area, HR - heart rate, bpm-beats per minute, SBP-systolic blood pressure, DBP - diastolic blood pressure. 
Table II. Echocardiographic M-mode and two-dimensional parameters

\begin{tabular}{|lccc|}
\hline Parameter & $\begin{array}{c}\text { SCA } \\
(n=60)\end{array}$ & $\begin{array}{c}\text { OSCD } \\
(n=16)\end{array}$ & $P$-value \\
\hline LAi $\left[\mathrm{cm} / \mathrm{m}^{2}\right]$ & $2.58 \pm 0.32$ & $2.25 \pm 0.28$ & $<0.001$ \\
\hline LAVi $\left[\mathrm{ml} / \mathrm{m}^{2}\right]$ & $47.7 \pm 11.5$ & $31.7 \pm 8.42$ & $<0.001$ \\
\hline LVDDi $\left[\mathrm{cm} / \mathrm{m}^{2}\right]$ & $3.47 \pm 0.37$ & $2.97 \pm 0.41$ & $<0.001$ \\
\hline LVSDi $\left[\mathrm{cm} / \mathrm{m}^{2}\right]$ & $2.12 \pm 0.31$ & $1.86 \pm 0.28$ & $<0.001$ \\
\hline LVDVi $\left[\mathrm{ml} / \mathrm{m}^{2}\right]$ & $77.9 \pm 17.2$ & $60.7 \pm 15.4$ & 0.001 \\
\hline LVSVi $\left[\mathrm{ml} / \mathrm{m}^{2}\right]$ & $31.6 \pm 7.70$ & $24.1 \pm 6.60$ & 0.001 \\
\hline FE Teicholz $(\%)$ & $68.2 \pm 6.69$ & $67.1 \pm 6.21$ & 0.527 \\
\hline FE Simpson $(\%)$ & $59.6 \pm 4.20$ & $60.9 \pm 3.36$ & 0.220 \\
\hline LVMi $\left[\mathrm{g} / \mathrm{m}^{2}\right]$ & $106.5 \pm 23.2$ & $75.19 \pm 20.1$ & $<0.001$ \\
\hline RAVi $\left[\mathrm{ml} / \mathrm{m}^{2}\right]$ & $31.8 \pm 7.75$ & $25.6 \pm 5.24$ & 0.002 \\
\hline RV diameter $[\mathrm{cm}]$ & $2.23 \pm 0.52$ & $2.23 \pm 0.59$ & 0.919 \\
\hline TAPSE $[\mathrm{cm}]$ & $2.77 \pm 0.43$ & $2.41 \pm 0.40$ & 0.004 \\
\hline
\end{tabular}

Values are expressed as means $\pm S D$. LAi - left atrial diameter index, LAVi - left atrial volume index, LVDDi-left ventricle diastolic diameter index, LVSDi - left ventricle systolic diameter index, LVDVi - left ventricle diastolic volume index, LVSVi - left ventricle systolic volume index, EF-ejection fraction, LVMi - left ventricular mass index, RAVi - right atrium volume index, RV - right ventricle, TAPSE - tricuspid annulus peak systolic excursion.

orated by a significant increase in cardiac index in our SCA patients, who have lower hemoglobin levels than the OSCD group. Left ventricular dilatation and eccentric hypertrophy found in these patients appear to be due to adaptation to the hyperkinetic state imposed by anemia [6, 7, 34]. Besides this, the right heart changes, mainly related to pulmonary hypertension, are well described.

In our study, the main focus was the evaluation of left heart chambers. A pertinent question is whether the left cavity dilation is exclusively secondary to the hyperkinetic state or is also related to structural histology changes in the myocardium. In our sample, the left cardiac chambers' size and mass correlated negatively with hemoglobin levels, favoring the first hypothesis. The presence of diastolic dysfunction points to this second hypothesis, but it was not proven regarding the systolic function. Two mechanisms have been postulated for development of diastolic dysfunction:

Table III. Doppler echocardiographic parameters

\begin{tabular}{|lccc|}
\hline Parameter & $\begin{array}{c}\text { SCA } \\
(n=60)\end{array}$ & $\begin{array}{c}\text { OSCD } \\
(n=16)\end{array}$ & $P$-value \\
\hline Mitral E wave [m/s] & $1.10 \pm 0.18$ & $0.97 \pm 0.18$ & 0.021 \\
\hline Mitral A wave [m/s] & $0.62 \pm 0.12$ & $0.51 \pm 0.12$ & 0.003 \\
\hline E/A ratio & $1.80 \pm 0.33$ & $1.97 \pm 0.50$ & 0.213 \\
\hline Lateral e' & $16.63 \pm 3.42$ & $17.17 \pm 2.68$ & 0.525 \\
\hline Septal e' & $12.05 \pm 2.02$ & $12.73 \pm 1.81$ & 0.232 \\
\hline E/e' ratio & $7.72 \pm 1.54$ & $6.70 \pm 1.65$ & 0.047 \\
\hline Abnormal E/e' ratio & $21(35 \%)$ & $1(6.3 \%)$ & 0.002 \\
\hline IVRT [ms] & $70.6 \pm 15.0$ & $65.0 \pm 10.0$ & 0.201 \\
\hline DTE [ms] & $160 \pm 15$ & $175 \pm 23$ & 0.069 \\
\hline Tricuspid S' [cm/s] & $17.2 \pm 3.01$ & $14.8 \pm 2.42$ & 0.002 \\
\hline TR velocity [m/s] & $2.52 \pm 0.35$ & $2.09 \pm 0.18$ & $<0.001$ \\
\hline PASP [mm Hg] & $30.2 \pm 7.15$ & $22.1 \pm 4.52$ & $<0.001$ \\
\hline AT [s] & $148 \pm 29$ & $144 \pm 23$ & 0.581 \\
\hline RVMPI & $0.31 \pm 0.05$ & $0.30 \pm 0.06$ & 0.791 \\
\hline
\end{tabular}

Values are expressed as means $\pm S D$ or number (\%). Mitral $E$ wave $-E$ wave maximum velocity at mitral inflow, Mitral $A$ wave $-A$ wave maximum velocity at mitral inflow, E/A ratio - ratio between the $E$ and $A$ wave velocities in the mitral flow, Lateral $e^{\prime}-e^{\prime}$ wave velocity at lateral mitral annulus, Septal e' - e' tissue Doppler image velocity on septal mitral annulus, E/e' ratio - ratio between mitral E wave and mean mitral annulus e' wave velocities, Tricuspid S' - S' wave tissue Doppler velocity at lateral tricuspid annulus, TR velocity - tricuspid regurgitation maximum velocity, PASP-pulmonary artery systolic pressure, AT-pulmonary flow acceleration time, RVMPI-RV myocardial performance index. 
Table IV. Two-dimensional left ventricular strain echocardiographic parameters

\begin{tabular}{|lccc|}
\hline Parameter & $\begin{array}{c}\text { SCA } \\
(n=28)\end{array}$ & $\begin{array}{c}\text { OSCD } \\
(n=16)\end{array}$ & $P$-value \\
\hline X 4C & $-17.14 \pm 2.77$ & $-17.64 \pm 3.08$ & 0.357 \\
\hline X 3C & $-18.29 \pm 3.26$ & $-19.00 \pm 2.48$ & 0.624 \\
\hline X 2C & $-17.85 \pm 3.08$ & $-16.29 \pm 2.27$ & 0.111 \\
\hline S Global & $-17.85 \pm 1.53$ & $-17.64 \pm 1.86$ & 0.849 \\
\hline S Global $\geq-18.9$ & $13(79 \%)$ & $7(50 \%)$ & 0.418 \\
\hline Age [years] & $24 \pm 6$ & $26 \pm 6$ & 0.170 \\
\hline Male gender & $14(50 \%)$ & $5(35 \%)$ & 0.392 \\
\hline
\end{tabular}

Values are expressed as means $\pm S D$ or number (\%). X $4 C$ - 4-chamber longitudinal strain, $X 3 C-3$-chamber longitudinal strain, $X 2 C-$ 2 -chamber longitudinal strain, X Global - left ventricular global longitudinal strain. ${ }^{*}$ Calculated in the sample evaluated for $2 D$ strain.

microcirculatory obstruction and myocardial iron deposit, in patients receiving multiple transfusions [9]. Nevertheless, a study of cardiac magnetic resonance, measuring myocardial iron deposits, found no correlation with diastolic dysfunction [35]. One limitation of studies of left cavities in SCA patients is to compose a control group with similar levels of hemoglobin to overcome the hemodynamic effects of anemia. In our sample, the E/e' ratio was greater in the SCA group. However, this can be explained for the hyperkinetic state because mitral E wave velocity was also greater in this group. In our sample, additionally, mitral A wave correlated significantly with hemoglobin levels.

We found no comparisons of echocardiography parameters in patients with SCA and OSCD in the literature. Our results in the SCA group were similar to other reports which showed left atrial and ventricular dilatation with preserved systolic function indexes in patients with SCA. higher values of E/e' ratio were observed in the SCA group, which does not necessarily represent diastolic dysfunction. Indeed, these results indicate a possible influence of hyperkinetic state leading to increased E wave velocity values. Sachdev et al. [19] reported a prevalence of $18 \%$ for diastolic dysfunction in SCA patients, but using the E/A ratio as the criterion. Tissue Doppler velocities must be more accurate for evaluation of diastolic function in SCA patients.

Regarding two-dimensional LV strain, there were no differences between groups and no correlation with hemoglobin levels. Our findings were similar to the study of Barbosa et al. [16], where strain changes in these patients were not detected, evaluating the same age range. The variability of normality criteria assumed by different authors makes the strain analysis difficult [27]. Depending on the reference values some patients may be classified as normal or abnormal. Speckle tracking study results were ambiguous, with change in a study of children in Tanzania and normal results in another study in Arabia [18]. These controversial results must be related to differences in technical
Table V. Correlations between hemoglobin levels and echocardiography parameters

\begin{tabular}{|lcc|}
\hline Parameter & $r$ & $P$-value \\
\hline LVDDi & -0.594 & $<0.001$ \\
\hline LVSDi & -0.465 & $<0.001$ \\
\hline LVEF & -0.037 & 0.820 \\
\hline LVMi & -0.491 & 0.001 \\
\hline LAVi & -0.637 & $<0.001$ \\
\hline LVGX & 0.075 & 0.641 \\
\hline Mitral E wave & -0.276 & 0.085 \\
\hline Mitral A wave & -0.340 & 0.032 \\
\hline E/A ratio & 0.212 & 0.190 \\
\hline Septal e' & 0.043 & 0.799 \\
\hline Lateral e' & -0.069 & 0.680 \\
\hline E/e' ratio & -0.164 & 0.333 \\
\hline
\end{tabular}

LVDDi - left ventricle diastolic diameter index, LVSDi - left ventricle systolic diameter index, LVEF - left ventricle ejection fraction, LVMi - left ventricle mass index, LAVi - left atrial volume index, LVGX - left ventricle global strain, Mitral E wave - E wave maximum velocity at mitral inflow, Mitral $A$ wave $-A$ wave maximum velocity at mitral inflow, E/A ratio - ratio between the $E$ and $A$ wave velocities in the mitral flow, Septal $e^{\prime}-e^{\prime}$ tissue Doppler image velocity on septal mitral annulus, Lateral $e^{\prime}-e^{\prime}$ wave velocity at lateral mitral annulus, E/e' ratio - ratio between mitral $E$ wave and mean mitral annulus e' wave velocities.

issues between studies or different evolution of disease in underdeveloped countries and point to the need of additional studies with left ventricular strain. We believe that studies with older patients will show any change caused by progressive microcirculatory ischemic changes in the myocardium.

With respect to the right chambers, higher levels of PASP and tricuspid regurgitation jet velocity in patients with SCA were detected. Interestingly, the S' wave tissue Doppler velocity and TAPSE were significantly higher in this group of patients. Although not previously described, these indexes may have been influenced by the hyperkinetic state imposed by anemia. The RV myocardial performance index showed no changes in our sample. Caldas showed that this index may be an early indicator of diastolic dysfunction [36]. 
The strength of the current study is that it is the first to compare the ventricular function and chamber dimensions and volumes between patients with SCA and patients with OSCD. We consider the small sample size to be the main limitation of our study, especially the small number of patients in the OSCD group. However, we believe that our results justify further research on the use of echocardiographic parameters as markers of severity in patients with sickle cell disease because they can be important in the follow-up of these patients.

In conclusion, there was an increase of left and right cavity dimensions in SCA patients compared to OSCD patients, without changes in systolic function in both groups in our sample. We found no differences in LV longitudinal two-dimensional strain analysis between groups. Furthermore, we found that the E/e' ratio is higher in SCA patients compared to OSCD patients, which may be due to the hyperkinetic state because the values of the mitral $E$ wave velocity were also higher in this group. Future prospects can compare the LV function and two-dimensional strain parameters in patients with similar levels of hemoglobin with or without SCA, to abrogate the impact of the hyperkinetic state of anemia and in older patients, assuming that systolic changes could appear later in the course of the disease.

\section{Conflict of interest}

The authors declare no conflict of interest.

\section{References}

1. Frenette PS, Atweh GF. Sickle cell disease: old discoveries, new concepts, and future promise. J Clin Invest 2007; 117: 850-8.

2. Hassell KL. Population estimates of sickle cell disease in the U.S. Am J Prev Med 2010; 38: S512-21.

3. Cançado RD, Jesus JA. A doença falciforme no Brasil. Sickle cell disease in Brazil. Rev Bras Hematol Hemoter 2007; 29: 203-6.

4. Machado RFP. Hipertensão arterial pulmonar associada à anemia falciforme. Sickle cell anemia-associated pulmonary arterial hypertension. J Bras Pneumol 2007; 33: 583-91.

5. Varat MA, Adolph RJ, Fowler NO. Cardiovascular effects of anemia. Am Heart J 1972; 83: 415-26.

6. Knight-Perry JE, Fuentes L, Waggoner AD, et al. Abnormalities in cardiac structure and function in adults with sickle cell disease are not associated with pulmonary hypertension. J Am Soc Echocardiogr 2011; 24: 1285-90.

7. Covitz W, Espeland M, Gallagher D, Hellenbrand W, Leff S, Talner N. The heart in sickle cell anemia. The Cooperative Study of Sickle Cell Disease (CSSCD). Chest 1995; 108: 1214-9.

8. Voskaridou E, Christoulas D, Terpos E. Sickle-cell disease and the heart: review of the current literature. $\mathrm{Br} J$ Haematol 2012; 157: 664-73.

9. Gladwin MT, Sachdev V. Cardiovascular abnormalities in sickle cell disease. J Am Coll Cardiol 2012; 59: 1123-33.
10. Fitzhugh CD, Lauder N, Jonassaint JC, et al. Cardiopulmonary complications leading to premature deaths in adult patients with sickle cell disease. Am J Hematol 2010; 85: 36-40.

11. Fleischer RA, Rubler S. Primary cardiomyopathy in nonanemic patients. Association with sickle cell trait. Am J Cardiol 1968; 22: 532-7.

12. Darbari DS, Kple-Faget P, Kwagyan J, Rana S, Gordeuk VR, Castro O. Circumstances of death in adult sickle cell disease patients. Am J Hematol 2006; 81: 858-63.

13. Mehari A, Gladwin MT, Tian X, Machado RF, Kato GJ. Mortality in adults with sickle cell disease and pulmonary hypertension. JAMA 2012; 307: 1254-6.

14. Poręba R, Gać P, Poręba $M$, et al. Left ventricular diastolic dysfunction and plasma asymmetric dimethylarginine concentration in persons with essential hypertension. Arch Med Sci 2015; 11: 521-9.

15. Sinha N, Devabhaktuni S, Kadambi A, McClung JA, Aronow WS, Lehrman SG. Can echocardiographically estimated pulmonary arterial elastance be a non-invasive predictor of pulmonary vascular resistance? Arch Med Sci 2014; 10: 692-700.

16. Barbosa MM, Vasconcelos MCM, Ferrari TCA, et al. Assessment of ventricular function in adults with sickle cell disease: role of two-dimensional speckle-tracking strain. J Am Soc Echocardiogr 2014; 27: 1216-22.

17. Di Maria MV, Hsu HH, Al-Naami G, et al. Left ventricular rotational mechanics in Tanzanian children with sickle cell disease. J Am Soc Echocardiogr 2015; 28: 340-6.

18. Ahmad H, Gayat E, Yodwut C, et al. Evaluation of myocardial deformation in patients with sickle cell disease and preserved ejection fraction using three-dimensional speckle tracking echocardiography. Echocardiography 2012; 29: 962-9.

19. Sachdev V, Machado RF, Shizukuda Y, et al. Diastolic dysfunction is an independent risk factor for death in patients with sickle cell disease. J Am Coll Cardiol 2007; 49: 472-9.

20. Abdul-Mohsen MF. Echocardiographic evaluation of left ventricular diastolic and systolic function in Saudi patients with sickle cell disease. I Saudi Heart Assoc 2012; 24: 217-24.

21. Lang RM, Badano LP, Mor-Avi V, et al. Recommendations for cardiac chamber quantification by echocardiography in adults: an update from the American Society of Echocardiography and the European Association of Cardiovascular Imaging. Eur Heart J Cardiovasc Imaging 2015; 16: 233-70.

22. Liszka J, Haberka M, Tabor Z, Finik M, Gąsior Z. Two-dimensional speckle-tracking echocardiography assessment of left ventricular remodeling in patients after myocardial infarction and primary reperfusion. Arch Med Sci 2014; 10: 1091-100.

23. Ciurzynski M, Bienias P, Irzyk K, et al. Heart diastolic dysfunction in patients with systemic sclerosis. Arch Med Sci 2014; 10: 445-54.

24. Nagueh SF, Appleton CP, Gillebert TC, et al. Recommendations for the evaluation of left ventricular diastolic function by echocardiography. Eur J Echocardiogr 2009; 10: 165-93.

25. Kusiak A, Wilinski J, Wojciechowska W, et al. Echocardiographic assessment of right ventricular function in responders and non-responders to cardiac resynchronization therapy. Arch Med Sci 2015; 11: 736-42.

26. Rudski LG, Lai WW, Afilalo J, et al. Guidelines for the echocardiographic assessment of the right heart in adults. J Am Soc Echocardiogr 2010; 23: 685-713. 
27. Yingchoncharoen T, Agarwal S, Popovic ZB, Marwick TH. Normal ranges of left ventricular strain: a meta-analysis. J Am Soc Echocardiogr 2013; 26: 185-91.

28. Marwick TH. Measurement of strain and strain rate by echocardiography: ready for prime time? J Am Coll Cardiol 2006; 47: 1313-27.

29. Mor-Avi V, Lang RM, Badano LP, et al. Current and evolv ing echocardiographic techniques for the quantitative evaluation of cardiac mechanics: ASE/EAE consensus statement on methodology and indications endorsed by the Japanese Society of Echocardiography. Eur J Echocardiogr 2011; 12: 167-205.

30. Denenberg BS, Criner G, Jones R, Spann JF. Cardiac function in sickle cell anemia. Am J Cardiol 1983; 51: 1674-8.

31. Manci EA, Culberson DE, Yang YM, et al.; Investigators of the Cooperative Study of Sickle Cell Disease. Causes of death in sickle cell disease: an autopsy study. $\mathrm{Br}$ J Haematol 2003; 123: 359-65.

32. Naoman SG, Nouraie M, Castro OL, et al. Echocardiographic findings in patients with sickle cell disease. Ann Hematol 2010; 89: 61-6.

33. Poludasu S, Ramkissoon K, Salciccioli L, Kamran H, Lazar JM. Left ventricular systolic function in sickle cell anemia: a meta-analysis. J Card Fail 2013; 19: 333-4.

34. Varat MA, Adolph RJ, Fowler NO. Cardiovascular effects of anemia. Am Heart J 1972; 83: 415-26.

35. Hankins JS, McCarville MB, Hillenbrand CM, et al. Ventricular diastolic dysfunction in sickle cell anemia is common but not associated with myocardial iron deposition. Pediatr Blood Cancer 2010; 55: 495-500.

36. Caldas MC, Meira ZA, Barbosa MM. Evaluation of 107 patients with sickle cell anemia through tissue Dopple and myocardial performance index. J Am Soc Echocardiogr 2008; 21: 1163-7. 